\title{
Phytotoxicity of essential oil from Piper nigrum L. On some selected food crops as a potential herbicide in Africa
}

\author{
Awojide S.H. ${ }^{1}$, Oyewole K.A. ${ }^{2 *}$, Abiona $0 . O^{3}{ }^{\text {., Agbaje A.W. }}{ }^{1}$ \\ ${ }^{1}$ Department of Pure and Applied Chemistry, Faculty of Basic and Applied Science, Osun State \\ University, Oshogbo, Nigeria. \\ ${ }^{2 *}$ Department of Chemical Engineering, Faculty of Engineering, Osun State University, \\ Oshogbo, Nigeria. \\ ${ }^{3}$ Department of Food Science and Technology, Faculty of Basic and Applied \\ Science, Osun State University, Oshogbo, Nigeria. \\ ${ }^{2 *}$ Corresponding author’s email: kehinde.fayemiwo@uniosun.edu.ng
}

Received: 25 February 2021 / Accepted: 26 May 2021 / Published online: 30th June 2021

\begin{abstract}
Phytotoxicity of the essential oil (EO) of Piper nigrum L. against Solanum lycopersicum L., Zea mays L. and Vigna unguiculata L. was studied. The GC-MS analysis of the essential oil of P. nigrum shows that linalool $(21.73 \%)$ was the major component of the essential oil. The EO retarded the growth of the root and the shoot of S. lycopersicum, $Z$. mays and $V$. unguiculata. The inhibition of the root ranged from $64.8-82.8 \%$ after 120 hours with a concentration of $4 \mathrm{~mL} / \mathrm{L}$, while for the shoot, $100 \%$ inhibition was observed with $4 \mathrm{~mL} / \mathrm{L}$ of the EO formulation after just 96 hours. The phytotoxic effect on the leaves was highest in V. unguiculata and least in S. lycopersicum. Phototoxicity was also observed when the $\mathrm{EO}$ formulations were applied to the root of the seedlings of $Z$. mays and $V$. unguiculata recorded $100 \%$ distress of the seedlings when $3 \mathrm{~mL} / \mathrm{L}$ of the graded concentration was used after 24 hours. EO from $P$. nigrum is a potential bio-herbicide with a wide spectrum of use on plants.
\end{abstract}

Keywords: Piper nigrum L., Solanum lycopersicum L., Zea mays L., Vigna unguiculata L., seedlings, bio-herbicide.

\section{INTRODUCTION}

The sparse land in the world is estimated to about 140,000,000 hectares; scattered around this ample space of land is over six thousand species of weeds which causes damage to agricultural products. Weeds are known to be responsible for reducing the quality and quantity of farm produce; they also compete with crops for essential material required for growth, including water, soil nutrients, carbon dioxide, and light (Anand et al., 2014). Weeds also are known to have a negative impact on crops in that they act as a host for diseases in food crops.

Several methods have been used to combat weed on farmlands; the two methods regarded as efficient methods for controlling weeds are hand weeding and the use of chemicals in the form of herbicides. The use of chemical herbicides in the control of weeds have proven to possess detrimental effects on the general environment (land and water bodies) and human health (Böcker et al., 2019). The use of herbicides is the most preferred methods of weed management among local farmers; this is due to its efficacy (Usman et al., 2012). The constant use of herbicides also results in the increased resistance of the weeds to the chemicals being used (Hiwa, 2017). This was confirmed by FAO (2004) who stated that the use of the chemical herbicide has led to the endangerment of three-quarter of the diversity of crops, also poses many environmental and public health concerns (Mancini et al., 2008). With so much concern on the health and environmental safety of both man and habitats in the rivers, the interest of man as being pushed towards the use of natural products which contains bioactive compounds as pesticides (Lim et al., 2017; Böcker et al., 2019). This form of pesticides 
is known as botanical herbicides, and they are having less toxicity or pose less risk to humans than synthetic herbicides. One great feature of botanical herbicides is the ability to be degradable, making them less prone to bioaccumulation in man or the environment.

For some decades, much research has focused on using plant-derived compounds as a safe herbicide in the environment which could be used in the replacement of synthetic or chemical herbicides (Duke et al., 2002; Javaid et al., 2006). Essential oils are natural products known for their diversified uses and have also been extensively investigated as potential pest control. Essential oils have been found to release allelopathic compounds, which could be applied to the management of weeds (Schleiden et al., 2019). Identifying and using these compounds can result in the development of eco-friendly bio-herbicides (Anand et al., 2014; Cordeau et al., 2016). In this context, our study aims to assess the herbicidal effect of Piper nigrum essential oil against Solanum lycopersicum, Zea mays and Vigna unguiculata.

\section{MATERIALS AND METHODS}

\section{Plant Materials}

Piper nigrum L. seeds were bought from Agbalata market in Badagary, Lagos state. The seeds of Solanum lycopersicum L., Zea mays L. and Vigna unguiculata L. were purchased at the International Institute of Tropical Agriculture (IITA) Ibadan, Oyo State, Nigeria. The seeds were identified at the Federal Research Institute of Nigeria (FRIN), Ibadan, Nigeria. The seeds were air-dried and ground to a powder.

\section{Essential Oil Distillation}

The seed of $P$. nigrum was ground into a powder and subjected to hydro-distillation using a modified Clevengertype apparatus for 6 hours. The extract was dried using anhydrous sodium sulphate. Essential oils were stored in airtight containers in a refrigerator at $4{ }^{\circ} \mathrm{C}$.

\section{GC-MS Analysis}

GC-MS was analysed using an Agilent 6890N instrument equipped with a flame ionization detector and Capillary column HP-5MS $(30 \mathrm{~m} \times 0.25 \mathrm{~mm} \times 0.25 \mu \mathrm{m})$. The components of the essential oil were identified on an Agilent Technologies 5973N mass spectrometer. The GC temperature was $60{ }^{\circ} \mathrm{C}$ for $1 \mathrm{~min}$ and ramped at $10{ }^{\circ} \mathrm{C}$ $\min ^{-1}$ to $180^{\circ} \mathrm{C}$ for $1 \mathrm{~min}$, and then ramped at $20^{\circ} \mathrm{C} \mathrm{min}^{-1}$ to $280{ }^{\circ} \mathrm{C}$ for $15 \mathrm{~min}$. The temperature of the injector was maintained at $270{ }^{\circ} \mathrm{C}$, a sample of $1 \mu \mathrm{L}$ were injected neat, with a split ratio of 1:10. Helium was the carrier gas that flowed at the rate of $1.0 \mathrm{~mL} \mathrm{~min}{ }^{-1}$. Spectra were scanned from 20 to $550 \mathrm{~m} / \mathrm{z}$ at 2 scans s$^{-1}$. The individual compounds were identified by MS; and their constituents' identity was confirmed by a comparison with their Kovat's retention index in relation to hydrocarbons relative to C8C32 n-alkanes and mass spectra with reference samples or with data already available in the NIST 2008, mass spectral both in the library and in the literature.

\section{Planting of Seedlings}

Plastic cups were filled with sandy loamy soil within $2 \mathrm{~cm}$ of the rim. About $50 \mathrm{~mL}$ of water was added to the soil in the plastic cup. Five $V$. unguiculata seeds were planted in each cup, maintaining a planting distance of $2 \mathrm{~cm}$ in a circular arrangement. The seeds were then covered with a large pinch of soil. The planted seedlings were placed in a greenhouse to allow seedlings to grow sufficient foliage. The same procedure was also used in the planting of $S$. lycopersicum and $Z$. mays seeds.

\section{Herbicidal Activity}

\section{Herbicide Formulation}

A liquid herbicide formulation of the essential oil was prepared by dissolving 5, 10, 15 and $20 \mu \mathrm{L}$ of the essential oil in $4 \mathrm{~mL}$ of deionized water and $1 \mathrm{~mL}$ of acetone (emulsifier) to prepare a concentration of 1,2,3 and 4 $\mathrm{mL} / \mathrm{L}$. A control formulation was prepared by dissolving 1 $\mathrm{mL}$ of acetone in $4 \mathrm{~mL}$ of deionized water.

\section{Growth Inhibitory Test}

For each formulation, ten (10) seeds were used. The seeds of $V$. unguiculata were placed on cotton wool in a Petri dish and soaked with water (the seeds were initially soaked in water for two hours to soften the outer coat for quicker germination). The essential oil formulation was applied on each seed in the Petri dish, and the length of growth of the root and shoot were measured and recorded daily for 5 days. A control experiment was performed for each test conducted. A complete set of controls was maintained and replicated thrice for each treatment. The experiment was repeated with the seeds of $S$. lycopersicum and $Z$. mays. The inhibition rate of the root and shoot lengths was calculated based on the following equation:

Inhibition rate $(\%)=\mathrm{T} / \mathrm{C} \times 100$

Where $\mathrm{T}$ is the length of the roots or shoots of the treated seedlings and $\mathrm{C}$ represents the length of the roots or shoots of the control seedlings.

\section{Soil Application}

For each formulation, ten (10) seeded plants of $V$. unguiculata was used. The essential oil formulation was applied to the soil around each plant to allow the herbicide formulation to get to the root, the number(s) of the plant in the pot showing sign of distress at an interval of 6 hours 
was noted and recorded for 48 hours. A control experiment was performed for each test conducted. A complete set of controls was maintained and replicated thrice for each treatment. The experiment was repeated for the seeds of $S$. lycopersicum and $Z$. mays.

\section{Foliar Application}

For each formulation, ten (10) seeded plants of $V$. unguiculata was used. The essential oil formulation was sprayed on the plants in the pot to allow the herbicide formulation to get to the leaf, the number(s) of the plant in the pot showing sign of distress at an interval of 6 hours was noted and recorded for 48 hours. The amount of solvent used was dependent upon the ability of the leaf surface to retain the solution. A control experiment was performed for each test conducted. The experiment was carried out in triplicate. The experiment was repeated for the seeds of $S$. lycopersicum and $Z$. mays.

\section{Data Analysis}

The experiments were conducted in three replicates. The data were subjected to one-way analysis of variance (ANOVA) with SPSS 2016, statistical software. Differences were considered to be significant at $\mathrm{P} \leq 0.05$.

\section{RESULTS AND DISCUSSION}

The result of root inhibitory activity of the essential oil of $P$. nigrum against $Z$. mays, $V$. unguiculata and $S$. lycopersicum is shown in Table 1 . For the root inhibitory activity of the essential oil of $P$. nigrum against $Z$. mays, the result revealed that the first sign of inhibitory activity of the root was observed after 48 hours and all the graded concentrations recorded different degrees of activity. The highest inhibitory activity on $Z$. mays root was observed by a concentration of $4 \mathrm{~mL} / \mathrm{L}$ (44.7\%). The inhibitory activities of the different doses increased with time. Batish et al. (2004) revealed that the essential oil from $E$. citriodora retarded the germination of test plants in a doseresponse relationship. This is similar to what was observed in this study. The highest root inhibitory activity of $64.8 \%$ was recorded after 72 hours, while the control experiment indicated no inhibitory activity throughout the hours of the experiment.

For the root inhibitory activity of $P$. nigrum essential oil against $V$. unguiculata, the first sign of activity against the root was recorded after 24 hours of the experiment; all the graded concentrations recorded root inhibitory activities. The concentration of $1 \mathrm{~mL} / \mathrm{L}$ recorded $5.9 \%$ root inhibitory activity of the roots of $V$. unguiculata, while $38.3 \%$ was observed with a concentration of 4 $\mathrm{mL} / \mathrm{L}$ after 24 hours. The root inhibitory activity of the graded concentrations of the essential oil of $P$. nigrum was dose and time-dependent. The highest activity recorded was after 120 hours of the experiment when a dose of 4 $\mathrm{mL} / \mathrm{L}$ was used, a root inhibitory activity of $80.8 \%$ was recorded for $V$. unguiculata roots. On the other hand, the inhibitory activity of the essential oil of $P$. nigrum against $S$. lycopersicum revealed a root inhibitory activity of $10 \%$ at 24 hours after a concentration of $1 \mathrm{~mL} / \mathrm{L}$ concentration was used. A higher root inhibitory activity was observed with high doses indicating it was dose and time-dependent. The result in Table 1 also showed that the highest root inhibitory activity was observed when $4 \mathrm{~mL} / \mathrm{L}$ of the essential oil formulation was used on the seeds for 120 hours $(82.8 \%)$.

The inhibitory activity of the graded concentrations of the essential oil of $P$. nigrum on the shoot of $Z$. mays, $V$. unguiculata and S. lycopersicum is shown in Table 2. The results indicated that on applying the essential oil of $P$. nigrum on the shoot of all the plants after 24 hours no inhibitory activity was recorded. Inhibitory activities were observed in the shoot of $Z$. mays, $V$. unguiculata and $S$. lycopersicum after 72 hours of the experiment. The initial sign of shoot inhibition was recorded for all seeds after 96 hours with the shoot inhibitory activities ranging from 32.3 - 40.6\% when a concentration of $1 \mathrm{~mL} / \mathrm{L}$ of the formulated essential oil of $P$. nigrum was used on the seeds. The seed of $Z$. mays recorded $100 \%$ inhibitory activity of the shoot when a dose of $4 \mathrm{~mL} / \mathrm{L}$ was used after 96 hours while the shoot of $V$. unguiculata and $S$. lycopersicum indicated $100 \%$ inhibition of the shoot with a concentration of $3 \mathrm{~mL} / \mathrm{L}$ after 96 hours.

Figure 1 showed the effect of the application of the graded concentrations of $P$. nigrum essential oil on the leaves of $Z$. mays, $V$. unguiculata and S. lycopersicum. The figure indicated that the lowest concentration of $1 \mathrm{~mL} / \mathrm{L}$ showed the phototoxic effect on the seedlings of all the plants by the discolouration of the leaves. $V$. unguiculata recorded $40 \%$ foliar effect, $20 \%$ by the seedlings of $Z$. mays and $10 \%$ by that of $S$. lycopersicum after 24 hours. The sign of phototoxicity was evidence in the decolouration of the leaves of the seedlings when the concentrations were applied to them. The seedlings of $V$. unguiculata recorded $100 \%$ toxicity when a dose of $2 \mathrm{~mL} / \mathrm{L}$ was used while the seedling of $S$. lycopersicum showed the least foliar effect after 24 hours.

The root zone inhibitory activity of the essential oil of $P$. nigrum against the seedlings of $Z$. mays, $V$. unguiculata and S. lycopersicum is indicated in Figure 2. The result showed a $100 \%$ root zone toxicity of $V$. unguiculata with $1 \mathrm{~mL} / \mathrm{L}$ does of the essential oil concentration. Complete toxicity of the root zone was recorded in $Z$. mays when a $3 \mathrm{~mL} / \mathrm{L}$ dose was applied in 24 hours. S. lycopersicum had the least 
root zone toxicity, the root zone activity of the essential oil formulated concentrations was evidence in the percentage of seedlings that wilted or could not stand firmly when the various concentrations were applied to the root zone.

Table 1: Percentage inhibitory activity of $P$. nigrum essential oil on $Z$. mays root, $V$. unguiculata root and S. lycopersicum root

\begin{tabular}{|c|c|c|c|c|c|}
\hline \multirow{2}{*}{$\begin{array}{c}\text { Duration } \\
\text { (hours) }\end{array}$} & \multicolumn{5}{|c|}{ Concentration $(\mathrm{ml} / \mathrm{l})$} \\
\hline & 1 & 2 & 3 & 4 & Control \\
\hline & \multicolumn{5}{|c|}{ Z. mays root } \\
\hline 24 & $0.0 \pm 0.0^{\mathrm{a}}$ & $0.0 \pm 0.0^{\mathrm{a}}$ & $0.0 \pm 0.0^{\mathrm{a}}$ & $0.0 \pm 0.0^{\mathrm{a}}$ & $0.0 \pm 0.0^{\mathrm{a}}$ \\
\hline 48 & $20.6 \pm 5.8^{b}$ & $31.1 \pm 5.8^{c}$ & $39.0 \pm 5.8^{c}$ & $44.7 \pm 5.8^{\mathrm{d}}$ & $0.0 \pm 0.0^{\mathrm{a}}$ \\
\hline 72 & $32.4 \pm 5.8^{b}$ & $38.2 \pm 5.8^{b}$ & $43.5 \pm 5.8^{c}$ & $51.8 \pm 5.8^{\mathrm{d}}$ & $0.0 \pm 0.0^{\mathrm{a}}$ \\
\hline 96 & $34.6 \pm 5.8^{b}$ & $43.2 \pm 5.8^{c}$ & $49.7 \pm 5.8^{c}$ & $58.2 \pm 5.8^{\mathrm{d}}$ & $0.0 \pm 0.0^{\mathrm{a}}$ \\
\hline \multirow[t]{2}{*}{120} & $47.3 \pm 5.8^{b}$ & $50.3 \pm 5.8^{c}$ & $52.0 \pm 5.8^{\mathrm{c}}$ & $64.8 \pm 5.8^{\mathrm{d}}$ & $0.0 \pm 0.0^{\mathrm{a}}$ \\
\hline & \multicolumn{5}{|c|}{ V. unguiculata root } \\
\hline 24 & $5.9 \pm 5.8^{b}$ & $28.9 \pm 5.8^{c}$ & $32.4 \pm 5.8^{\mathrm{d}}$ & $38.29 \pm 1.1^{\mathrm{d}}$ & $0.0 \pm 0.0^{\mathrm{a}}$ \\
\hline 48 & $22.2 \pm 5.8^{\mathrm{b}}$ & $28.9 \pm 5.8^{c}$ & $37.8 \pm 5.8^{c}$ & $46.7 \pm 5.8^{d}$ & $0.0 \pm 0.0^{\mathrm{a}}$ \\
\hline 72 & $27.5 \pm 5.8^{\mathrm{b}}$ & $32.4 \pm 5.8^{c}$ & $59.1 \pm 5.8^{\mathrm{d}}$ & $63.6 \pm 5.8^{\mathrm{e}}$ & $0.0 \pm 0.0^{\mathrm{a}}$ \\
\hline 96 & $46.7 \pm 5.8^{b}$ & $48.9 \pm 5.8^{b}$ & $64.9 \pm 5.8^{c}$ & $74.5 \pm 5.8^{\mathrm{d}}$ & $0.0 \pm 0.0^{\mathrm{a}}$ \\
\hline \multirow[t]{2}{*}{120} & $55.3 \pm 5.8^{b}$ & $67.5 \pm 5.8^{c}$ & $70.0 \pm 5.8^{c}$ & $80.8 \pm 5.8^{\mathrm{d}}$ & $0.0 \pm 0.0^{\mathrm{a}}$ \\
\hline & \multicolumn{5}{|c|}{ S. lycopersicum root } \\
\hline 24 & $10.0 \pm 5.8^{b}$ & $32.9 \pm 5.8^{c}$ & $38.4 \pm 5.8^{\mathrm{d}}$ & $40.2 \pm 5.8^{\mathrm{d}}$ & $0.0 \pm 0.0^{\mathrm{a}}$ \\
\hline 48 & $25.2 \pm 5.8^{\mathrm{b}}$ & $36.2 \pm 5.8^{c}$ & $40.4 \pm 5.8^{c}$ & $48.7 \pm 5.8^{\mathrm{d}}$ & $0.0 \pm 0.0^{\mathrm{a}}$ \\
\hline 72 & $30.5 \pm 5.8^{b}$ & $32.4 \pm 5.8^{c}$ & $61.3 \pm 5.8^{d}$ & $65.6 \pm 5.8^{\mathrm{e}}$ & $0.0 \pm 0.0^{\mathrm{a}}$ \\
\hline 96 & $50.7 \pm 5.8^{b}$ & $48.9 \pm 5.8^{b}$ & $67.2 \pm 5.8^{c}$ & $78.5 \pm 5.8^{d}$ & $0.0 \pm 0.0^{\mathrm{a}}$ \\
\hline 120 & $58.3 \pm 5.8^{b}$ & $67.5 \pm 5.8^{c}$ & $73.3 \pm 5.8^{\mathrm{c}}$ & $82.8 \pm 5.8^{\mathrm{d}}$ & $0.0 \pm 0.0^{\mathrm{a}}$ \\
\hline
\end{tabular}

Values were means of three replicates \pm S.D; Means within each row for each treatment with different superscripts are significantly $(\mathrm{P}<0.05)$ different

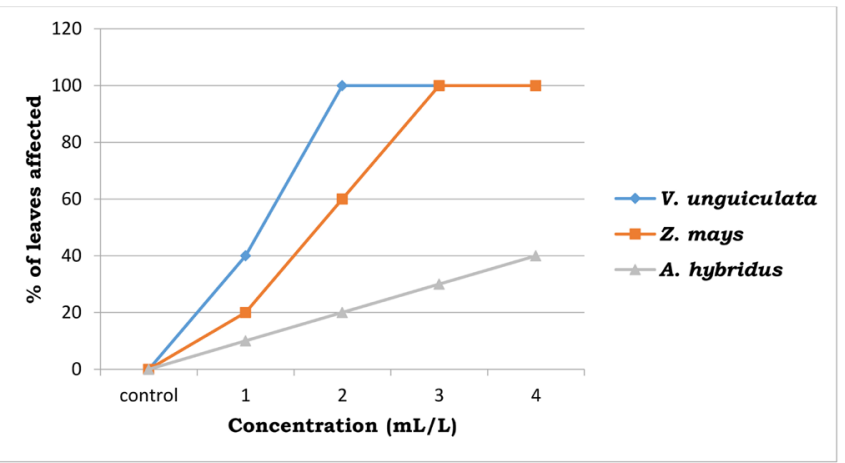

Figure 1: Percentage foliar activity of $P$. nigrum essential oil on $V$. unguiculata, Z. mays and S. lycopersicum after 24 hours

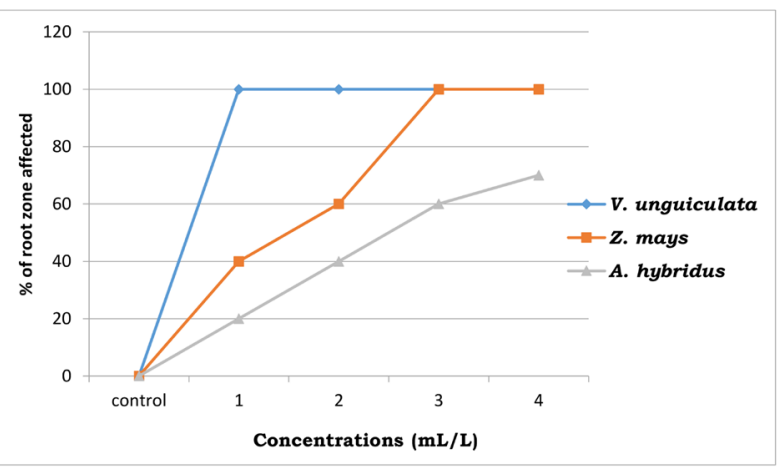

Figure 2: Percentage root zone inhibitory activity of $P$. nigrum essential oil on $V$. unguiculata, Z. mays and S. lycopersicum after 24 hours 
Table 2: Percentage inhibitory activity of P. nigrum essential oil on $Z$. mays shoot, $V$. unguiculata shoot and S. lycopersicum shoot

\begin{tabular}{|c|c|c|c|c|c|}
\hline \multirow{2}{*}{$\begin{array}{l}\text { Duration } \\
\text { (hours) }\end{array}$} & \multicolumn{5}{|c|}{ Concentration $(\mathrm{ml} / \mathrm{l})$} \\
\hline & 1 & 2 & 3 & 4 & Control \\
\hline & \multicolumn{5}{|c|}{ Z. mays shoot } \\
\hline 24 & $0.0 \pm 0.0^{\mathrm{a}}$ & $0.0 \pm 0.0^{\mathrm{a}}$ & $0.0 \pm 0.0^{\mathrm{a}}$ & $0.0 \pm 0.0^{\mathrm{a}}$ & $0.0 \pm 0.0^{\mathrm{a}}$ \\
\hline 48 & $0.0 \pm 0.0^{\mathrm{a}}$ & $0.0 \pm 0.0^{\mathrm{a}}$ & $0.0 \pm 0.0^{\mathrm{a}}$ & $0.0 \pm 0.0^{\mathrm{a}}$ & $0.0 \pm 0.0^{\mathrm{a}}$ \\
\hline 72 & $0.0 \pm 0.0^{\mathrm{a}}$ & $0.0 \pm 0.0^{\mathrm{a}}$ & $0.0 \pm 0.0^{\mathrm{a}}$ & $0.0 \pm 0.0^{\mathrm{a}}$ & $0.0 \pm 0.0^{\mathrm{a}}$ \\
\hline 96 & $32.3 \pm 5.8^{b}$ & $41.9 \pm 5.8^{\mathrm{c}}$ & $75.8 \pm 5.8^{\mathrm{d}}$ & $100.0 \pm 0.0^{\mathrm{e}}$ & $0.0 \pm 0.0^{\mathrm{a}}$ \\
\hline \multirow[t]{2}{*}{120} & $56.9 \pm 5.8^{\mathrm{b}}$ & $65.8 \pm 5.8^{\mathrm{c}}$ & $86.8 \pm 5.8^{\mathrm{d}}$ & $100.0 \pm 0.0^{\mathrm{e}}$ & $0.0 \pm 0.0^{\mathrm{a},}$ \\
\hline & \multicolumn{5}{|c|}{ V. unguiculata shoot } \\
\hline 24 & $0.0 \pm 0.0^{\mathrm{a}}$ & $0.0 \pm 0.0^{\mathrm{a}}$ & $0.0 \pm 0.0^{\mathrm{a}}$ & $0.0 \pm 0.0^{\mathrm{a}}$ & $0.0 \pm 0.0^{\mathrm{a}}$ \\
\hline 48 & $0.0 \pm 0.0^{\mathrm{a}}$ & $0.0 \pm 0.0^{\mathrm{a}}$ & $0.0 \pm 0.0^{\mathrm{a}}$ & $0.0 \pm 0.0^{\mathrm{a}}$ & $0.0 \pm 0.0^{\mathrm{a}}$ \\
\hline 72 & $0.0 \pm 0.0^{\mathrm{a}}$ & $0.0 \pm 0.0^{\mathrm{a}}$ & $0.0 \pm 0.0^{\mathrm{a}}$ & $0.0 \pm 0.0^{\mathrm{a}}$ & $0.0 \pm 0.0^{\mathrm{a}}$ \\
\hline 96 & $38.6 \pm 5.8^{b}$ & $75.8 \pm 5.8^{c}$ & $100 \pm 0.0^{\mathrm{d}}$ & $100 \pm 0.0^{\mathrm{d}}$ & $0.0 \pm 0.0^{\mathrm{a}}$ \\
\hline \multirow[t]{2}{*}{120} & $53.7 \pm 5.8^{\mathrm{b}}$ & $83.50 \pm 5.8^{\mathrm{c}}$ & $100 \pm 0.0^{\mathrm{d}}$ & $100 \pm 0.0^{\mathrm{d}}$ & $0.0 \pm 0.0^{\mathrm{a}}$ \\
\hline & \multicolumn{5}{|c|}{ S. lycopersicum shoot } \\
\hline 24 & $0.0 \pm 0.0^{\mathrm{a}}$ & $0.0 \pm 0.0^{\mathrm{a}}$ & $0.0 \pm 0.0^{\mathrm{a}}$ & $0.0 \pm 0.0^{\mathrm{a}}$ & $0.0 \pm 0.0^{\mathrm{a}}$ \\
\hline 48 & $0.0 \pm 0.0^{\mathrm{a}}$ & $0.0 \pm 0.0^{\mathrm{a}}$ & $0.0 \pm 0.0^{\mathrm{a}}$ & $0.0 \pm 0.0^{\mathrm{a}}$ & $0.0 \pm 0.0^{\mathrm{a}}$ \\
\hline 72 & $0.0 \pm 0.0^{\mathrm{a}}$ & $0.0 \pm 0.0^{\mathrm{a}}$ & $0.0 \pm 0.0^{\mathrm{a}}$ & $0.0 \pm 0.0^{\mathrm{a}}$ & $0.0 \pm 0.0^{\mathrm{a}}$ \\
\hline 96 & $40.6 \pm 5.8^{b}$ & $80.2 \pm 5.8^{c}$ & $100 \pm 0.0^{\mathrm{d}}$ & $100 \pm 0.0^{\mathrm{d}}$ & $0.0 \pm 0.0^{\mathrm{a}}$ \\
\hline 120 & $55.7 \pm 5.8^{\mathrm{b}}$ & $86.50 \pm 5.8^{c}$ & $100 \pm 0.0^{\mathrm{d}}$ & $100 \pm 0.0^{\mathrm{d}}$ & $0.0 \pm 0.0^{\mathrm{a}}$ \\
\hline
\end{tabular}

Values were means of three replicates \pm S.D; Means within each row for each treatment with different superscripts are significantly $(\mathrm{P}<0.05)$ different

Table 3 revealed the major components of the essential oil of $P$. nigrum. Linalool was the major component with a percentage of 21.73 which is an oxygenated monoterpene, followed by Sesquiterpene hydrocarbons, Caryophyllene (7.35), $\gamma$ Bisabolene (8.75) and $\beta$ Farnescene (6.12). Ibáńez and Blázquez (2018) also reported the presence of Linalool, Caryophyllene and $\gamma$ Bisabolene in the essential oil of peppermint. Andriana et al. (2019) reported that $\beta$-caryophyllene $(51.12 \%)$ and $\beta$-thujene $(20.58 \%)$ were the dominant components of $P$. nigrum essential oil. Singh et al. (2002) in their study observed that citronellal and linalool possessed a high degree of phytotoxicity, leading to complete inhibition of germination of seedlings. Lavender essential oil composed of $36.8 \%$ linalool was classified as a medium phytotoxic essential oil (Synowiec et al., 2016). This indicates that the major components of this oil, linalool, could be responsible for the phytotoxicity of the essential oil on the various plants.
Table 3: Major constituents of four essential oil of $P$. nigrum

\begin{tabular}{lc}
\hline Components & \% in Sample \\
\hline Linalool & 21.73 \\
Caryophyllene & 7.35 \\
$\gamma$ Bisabolene & 8.75 \\
$\beta$ Farnescene & 6.12 \\
\hline
\end{tabular}

The result of the seed germination experiment (root and shoot) showed that the essential oil of $P$. nigrum recorded phytotoxicity against seed germination. This is evidence in the root and shoot growth compared with that of the control experiments that had no essential oil. The growth of the root and shoot were retarded when the various concentrations of formulated essential oils were applied. This was similar to what was reported by Ibáñez and Blázquez (2018), who indicated the phytotoxicity of peppermint essential oil against seed germination. The result obtained indicated 
that of all the seeds experimented on with the essential oil of $P$. nigrum, S. lycopersicum recorded the highest root inhibitory activity while $Z$. mays showed the least activity. This was similar to what was reported by Ibáñez and Blázquez (2018) who reported that tomato showed greater toxicity with the essential oil of peppermint than maize and rice. Similar result was recorded for the shoot of the seeds. The results indicated that the inhibitory activities of the different graded concentrations were higher on the roots than the shoots (Javaid, 2010; Issakul, 2013). This could be indicative of the fact that the root shows sign of growth earlier than the shoots.

The decolouration of the leaves of the seedlings of $Z$. mays, $V$. unguiculata and $S$. lycopersicum was evidence in the phytotoxicity of the essential oil of $P$. nigrum. V. unguiculata showed higher foliar activity in all dose used while the least activity was recorded in S. lycopersicum. The variation in toxicity effect on the essential oil concentrations on the plants could be as a result of the leaves orientation or morphology. The leaves of $V$. unguiculata was broad enough to allow the formulated concentrations of the essential oil to be retained on the leaves compared to those of $Z$. mays and $S$. lycopersicum.

The application of the formulated concentrations of the essential oil of $P$. nigrum on the root zone of the seedlings of $Z$. mays, $V$. unguiculata and S. lycopersicum indicated distress the seedlings were subjected. The distress of the plants was observed in the percentage of the seedlings which wilted or bent and unable to stand upright compared to the control experiment, $S$. lycopersicum showed the least activity. Faria et al. (2015) showed that some essential oils application induced shoot chlorosis as well as drooping, the same was observed in this study.

\section{CONCLUSION}

In conclusion the essential oil of $P$. nigrum showed herbicidal activity against Z. mays, $V$. unguiculata and S. lycopersicum, this indicated that the essential oil had a wide spectrum of use on plants. This essential oil has the potential of being a botanical herbicide with a wide spectrum. Low doses of it can also be a potential alternative to synthetic agrochemicals

\section{REFERENCES}

Anand, T. P., Chellaram, C., Praveen, M. M., Guru. S. G., \& Shanthini, C. F. (2014). Herbicidal and growth promoter activity of three saltmarsh plants from Pulikat coast. International Journal of Chem. Tech. Research, 6(2), 1051-1054.

Andriana, Y., Xuan, T. D., Quy, T. N., Tran, H. D., \& Le, Q. T. (2019). Biological activities and chemical constituents of essential oils from Piper cubeba Bojer and Piper nigrum L. Molecules, 24(10), 1876.

Batish, D. R., Setia, N., Singh, H. P., \& Kohli, R. K. (2004). Phytotoxicity of lemon-scented eucalyptus oil and its potential use as a bioherbicide. Crop Protection, 23(12), 1209-1214.

Böcker, T., Möhring, N., \& Finger, R. (2019). Herbicide free agriculture? A bio-economic modelling application to swiss wheat production. Agricultural Systems, 173, $378-392$.

Cordeau, S., Triolet, M., Wayman, S., Steinberg, C., \& Guillemin, J. P. (2016). Bioherbicides: dead in the water? A review of the existing products for integrated weed management. Crop Protection, 87, 44-49.

Duke, S. O., Dayan, F. E., Aliota, G., \& Romagni, J. G. (2002). Chemicals from nature for weed management. Weed Science, 50, 138-151.

FAO. (2004). Biological diversity is fundamental to agriculture and food production. Retrieved from http:// ftp.fao.org/docrep/fao/006/y5418e/y5418e00.pdf.

Faria, J. M. S., Sena, I., Moiteiro, C., Bennett, R., Mota, M., \& Figueiredo, A. C. (2015) Nematoxic and phytotoxic activity of Satureja montana and Ruta graveolens essential oils on Pinus pinaster shoot cultures and P. pinaster with Bursaphelenchus xylophilus in vitro co-cultures. Ind. Crops Production, 7, 59-65.

Hiwa, M. A. (2017). Phytochemical screening, total phenolic content and phytotoxic activity of corn (Zea mays) extracts against some indicator species. Natural Product Research, 32, 714-718.

Ibánez, M. D. \& Blázquez, M. A. (2018). Phytotoxicity of essential oils on selected weeds: potential hazard on food crops. Plants, 7(4), 79.

Issakul, K. (2013). Herbicidal efficiency of Aglaia odorata extracts against Mimosa pigra L. American Journal of Research Communication, 1(5), 240-241.

Javaid, A., Shafique, S., \& Shafique, S. (2010). Herbicidal activity of Withania somnifera against Phalaris minor. Natural Product Research, 24(15), 1457-1468.

Javaid, A., Shafique, S., Bajwa, R., \& Shafique, S. (2006). Effect of aqueous extracts of allelopathic crops on germination and growth of Parthenium hysterophorus L. South African. Journal of Botany, 72, 609-612.

Lim, C. J., Basri, M., Ee, G. C. L., \& Omar, D., (2017). Phytoinhibitory activities and extraction optimization of potent invasive plants as eco-friendly weed suppressant against Echinochloa colona (L.) link. Industrial Crops and Products, 100, 19-34.

Mancini, F., Termorshuizen, A. J., Jiggins, J. L. S., \& van-Bruggen, A. H. C. (2008). Increasing the environmental and social sustainability of cotton farming through farmer education in Andhra Pradesh. Indian Agricultural Systems, 96, 16-25. 
Schleiden, M., Carvalho, S., Andrade-vieira, L. F. et al., (2019). Allelopathic potential and phytochemical screening of ethanolic extracts from five species of Amaranthus spp. in the plant model Lactuca sativa. Scientia Horticulturae, 245, 90-98.

Singh, H. P., Batish, D. R., Kaur, S., Ramezani, H., \& Kohli, R. K. (2002). Comparative phytotoxicity of four monoterpenes against Cassia occidentalis. Annals of Applied Biology, 141(2), 111-116.

Synowiec, A., Kalemba, D., Drozdek, E., \& Bocianowski, J. (2016). Phytotoxic potential of essential oils from temperate climate plants against the germination of selected weeds and crops. Journal of Pest Science, 90(1), 407-419.

Usman, K., Ullah, I., Khan, S. M., Khan, M. U., Ghulam, S., \& Khan, M. A. (2012). Integrated weed management through tillage and herbicides for wheat production in rice-wheat cropping system in Northwestern Pakistan. Journal of Integrative Agriculture, 11(6), 946-953. 